This item was submitted to Loughborough's Research Repository by the author.

Items in Figshare are protected by copyright, with all rights reserved, unless otherwise indicated.

\title{
Probing user values in the home environment within a technology driven Smart Home project
}

PLEASE CITE THE PUBLISHED VERSION

PUBLISHER

(C) Springer Verlag

LICENCE

CC BY-NC-ND 4.0

\section{REPOSITORY RECORD}

Haines, Victoria, Val Mitchell, Catherine Cooper, and Martin Maguire. 2019. "Probing User Values in the Home Environment Within a Technology Driven Smart Home Project". figshare. https://hdl.handle.net/2134/2288. 


\title{
Probing user values in the home environment within a technology driven Smart Home project
}

\author{
Victoria Haines, Val Mitchell, Catherine Cooper, Martin Maguire \\ Ergonomics and Safety Research Institute \\ Loughborough University \\ Leicestershire \\ LE11 3UZ \\ UK \\ +44 (0)1509 283300 \\ +44 (0)1509 283360 \\ v.j.haines@lboro.ac.uk \\ v.a.mitchell@lboro.ac.uk \\ c.cooper@lboro.ac.uk \\ m.c.maguire@lboro.ac.uk \\ www.lboro.ac.uk/esri
}

\begin{abstract}
Smart Home technology looks set to become an increasingly common feature of domestic life. However commercial desire for technical innovation rather than explicit user needs are often the driving force behind the development of Smart Home products and services. This study adapts the Cultural Probe approach developed by Gaver et al [2] to collect primarily visual data about what people value within their home environment. Whereas Cultural Probes are predominantly used to build empathy with users when designing product concepts, this approach attempted to provide similarly fun and engaging prompts for data collection when the design process and project context required more structured consideration of user needs. This paper presents the method developed, project findings and recommendations on how the method should be applied.
\end{abstract}

\section{Keywords}

Probes, Photo Study, domestic environments, values, smart homes, usercentred design, technology 


\section{Introduction}

This study was conducted by the Ergonomics and Safety Research Institute (ESRI) at Loughborough University as part of two large technical programmes under The Application Home Initiative (TAHI), with matched funding from the UK's Department for Trade and Industry. These programmes developed and trialled two prototype Smart Home systems: one to improve energy monitoring and equipment management in the home (Equipment Management Trial); the other to provide aggregated information, energy monitoring and entertainment services to the householder (Services Aggregation Trial). ESRI's role in both projects was to provide human factors support within a technology driven development process [1]. Product concepts were already determined at the start of the projects by the technology providers within each project consortia. Both projects focused upon the development of technical solutions that integrated off the shelf and innovative technologies in order to demonstrate the commercial and technical feasibility of providing Smart Home services within existing (rather than purpose built homes). (For clarity the two projects will be treated as one within this paper as ESRI's role within both was essentially the same).

Although ESRl's role mainly involved designing and evaluating user interfaces for the emerging equipment and services, the authors wished to take the opportunity to promote User Centred Design amongst the largely technology focused project partners. This paper describes a Photo Study method to record the domestic context inspired by the Cultural Probe approach of Gaver et al [2] developed to meet the demands of such a technology driven development process. The goal was to convince the technical partners that users do not always share their views concerning the value of Smart Home technologies and that many of the behaviours currently used to organise daily living do not require advanced technologies to succeed. The aim was not to push a Luddite agenda, rather to help technologists understand where technological solutions are currently valued by consumers and to highlight domestic contexts of use where products must particularly meet the emotional as well as functional needs of users in order to be valued and accepted. The method is described and its strengths and limitations discussed in relation to the project context. The appropriateness of applying a Probe approach within a technology focused design process is then discussed and conclusions drawn about the wider applicability of the method.

\section{Background}

In contrast to the more extensive body of literature on the social context of computer use in the workplace there is little written on the social context of computer use in the home [3]. Work by Venkatesh [4] introduces the idea of two key constructs - the social space and the technological space which define the main parameters of household-technology interaction. The computer industry has a strong interest in integrating computer technology into the home, yet there are few sources of knowledge on how 
this works and fits in practice [5]. Many technology providers have sound knowledge of the technology they produce but not of the social context of its use $[4,6]$. Visions of what technology can do for people are rarely based on any comprehensive understanding of needs and in some cases are blatant technology push [7]. When technology is incorporated within the home, the people who live with the technology on a day-to-day basis have tended to have been overlooked $[7,8]$.

We wished to examine the home environment as a social space in order to understand the role technology plays within everyday household activities and interactions. In particular the study was designed to explore the perceived value of technology in the home - in what use contexts was technology valued and why? What did this tell us about the likely acceptability of the Smart Home solutions being developed within the project and how should this understanding of user needs drive the development of future Smart Home products and services? Gaver [9] states that unless people start to respect the full range of values that make us human, the technologies we build are likely to be dull and uninteresting at best, and de-humanising at worst.

A number of factors drove the development of the chosen approach:

- An engaging data collection approach was required that respected the privacy of the householders and encouraged individuals to take part in the study during their leisure orientated time at home.

- The opportunity to conduct extensive user studies was not provided by the project structure. A 'discount' method was therefore needed that fitted the resources and timescales of the project.

- The output of the method needed to be in a form that was meaningful to the technology focused project partners who mainly had engineering backgrounds.

- The authors wished to refresh their own enthusiasm for engagement with users within a project that was facing numerous technical challenges relating to the task of integrating diverse technologies within the home environment.

Many observation based studies carried out in domestic settings adopt an ethnomethodological approach drawing upon techniques developed within the domain of computer supported co-operative work (CSCW). However researchers from the CSCW tradition admit that even "quick and dirty" ethnography [10] that typically involves the researcher spending several days continuously present within the workplace is unlikely to be acceptable to many households. "A pragmatic as opposed to methodologically-purist stance" [11] to data collection is therefore required in order to investigate the home environment. Investigating the use of technology in the home requires trust to be established between researchers and participants [12]. Even when trust is established, O'Brien and Rodden [13] acknowledge that many aspects of the domestic routines are too personal to be observed. Crabtree and Rodden [14] argue however that it is a misconception to view the home as a particularly difficult domain to observe through first hand observation and in fact workplace studies can raise greater barriers to data collection. Access to 
the home rather than the workplace can be simpler to negotiate and there are typically less political issues to be managed. Once the acceptance and trust of study participants has been gained, they report from their own research experiences that people are surprisingly open to being directly or indirectly observed (e.g. using video cameras) within the home environment. However gaining the acceptance and trust of study participants takes time and requires flexibility within the study design. Crabtree and Rodden (2004) describe how the location of video cameras and recording times had to be negotiated with study participants during a longitudinal study of household activities. They also report that when a subsequent set of participants were asked to video and log the flow of communications in and out of the home, that not all details were reported because of "a variety of sensitive household matters". Therefore Crabtree and Rodden, whilst rightly cautioning against exaggerating the demands of home based research, still affirm the need for methods that allow participants some degree of control over data collection.

We wished to counter such privacy concerns by placing data collection firmly in the hands of the study participants. The use of a data collection method based upon the Cultural Probes approach of Gaver et al [2] appeared at first glance to meet our need for a self administered and engaging data collection tool. However the context for applying Probes within our project was very different from the artist / designer research context of Gaver et al and actually contrary to the design culture that they are looking to embody within the Cultural Probe approach (Gaver et al 2004). A further research question therefore arose - can Probes be used usefully beyond concept design to stimulate consideration of user needs within a technology push development process? In particular can the subjective and emotive responses generated by Probe tasks be systematically analysed in a meaningful way to facilitate the assimilation of the Probe outputs by technologists who prefer informative rather than inspirational guidance?

The Cultural Probe approach was developed to "provoke inspirational responses" from elderly users within the EC Presence project [15]. Gaver et al's [2] Probes consisted of a package of maps, postcards, cameras and other materials that were taken home by the study participants to fill in or use and then send back to the project researchers. The materials were deliberately aesthetic, attractive and provocative in order to stimulate the users to think about their lives in unconventional ways. The Probes were introduced to the study participants as a way for the designers to get to know the users and for the users to get to know the designers. The intention was to provide insight into the culture and values of the target user population in a way that countered any stereotypes held by the designers and researchers. Gaver et al [2] describe how the Probes were not intended to provide an objective account of the users needs, nor were they intended to define a set of problems. Instead the Probes were intended to create an "impressionistic account" of the users "beliefs and desires, their aesthetic preferences and cultural concerns."

The concept of using design-orientated user research tools based on self- 
documentation ('Probes') has been extended by others to meet a much wider range of research requirements. Mättelmaki [16] provides four reasons for applying Probes based on a comprehensive review of Probe based approaches: to provide inspiration, information, participation and dialogue. Gaver's Cultural Probes are according to Mättelmaki an example of 'inspiration Probes'. Objectivity is avoided when analysing the inspirational Probe responses; instead the raw Probe data are used in a "designerly way" to create personas, frame problem spaces and capture design ideas.

Information Probes are used more directly to elicit information about user needs. The information Probe tasks are primarily descriptive and leave less room for interpretation than the Probes for inspiration. Information Probes were used by Hemmings et al [17] to analyse user needs for future systems designed to support patient care within a sheltered housing complex for former psychiatric patients. The Probe tasks were used in preference to observation based methods as being watched was likely to be unacceptable and potentially damaging for those with paranoia and related conditions (see also Rouncefield et al [18]).

Mättelmaki also describes how Probes can be used within Participatory Design (e.g. Muller [19]) to provoke users to use their imaginations, express their ideas and think more widely about possible solutions for their needs. Both inspirational and information Probes can be used to facilitate the participation of users in design. Hutchinson et al's [20] Technology Probes, used to provoke users to consider their needs for remote interaction with others, are an example of information Probes being used in this manner. Mättelmaki's final role for Probes is to facilitate dialogue between users, researchers and designers. Hemmings et al [17] saw their information Probes as an opportunity to build trust with the hostel residents using the delivery and collection of the Probe toolkits as part of this process.

Gaver et al [21] express concern about Probes being used beyond their original inspirational context: "People seem unsatisfied with the playful, subjective approach embodied by the original Probes and so design theirs to ask specific questions and produce comprehensive results. They summarize them, analyze them, even use them to produce requirements analyses." Analysing Probe responses, they argue, raises the following concerns:

- Asking unambiguous questions reduces the likelihood of receiving surprising answers that can inspire innovative thinking.

- Summarising results leads to consideration of average users which can also lead to the loss of inspiring individual detail.

- Presentation of analysed and summarised results to designers instead of raw data reduces exposure to the users' world.

- Attempting to justify the Probe returns in scientific terms constrains imaginative engagement with the outcomes.

In particular they are concerned that the Probes used in their original form embody an approach to design that encourages "subjective engagement, 
empathetic interpretation and a pervasive sense of uncertainty as positive values for design". Adopting a scientific approach to using Probes is perceived by Gaver et al. as contrary to their original concept. Mättelmaki, although more comfortable than Gaver et al. with the concept of information Probes, also concludes that Probe outputs are difficult to analyse in any systematic way and therefore often unsuited to meeting the demands of product development encountered beyond the concept design stage. When concrete answers are required to specific questions, she concludes that Probe tasks are often too unfocused, subjective and emotional. Probes are therefore best applied within the early concept design phase where objectivity and systematic analysis of needs are not the priority.

Whilst accepting that we were losing much of the essence of true "Probology" [21], our research needs were still felt to justify a Probe based method of data collection. Most significantly this approach provided the opportunity to explore whether highly visual and subjective Probe outputs could be systematically analysed in order to provide more structured and informative output suited to the technology focused culture of the project.

\section{Method}

The study participants were issued with mission packs, shown in Figure 1, which contained all the resources they needed to complete the Probe tasks. The packs were designed to be stimulating and fun to complete yet structured to constrain data collection to the specific needs of project. The pack included:

- A participant information sheet

- Photograph record book

- Seven sealed mission envelopes

- Digital Camera and spare batteries

\section{Figure 1 in here.}

Participants were not informed of the study's detailed aims, instead they were briefed on a broad 'values' study and were asked to complete 7 missions to capture images in and around their home. This provided a structured enquiry approach, where participants where free to take images of anything within their home, but within a structured framework. The missions were developed to standardise the context of the photographs, and included issues derived from previous focus group research within the project and the interests of the technology partners. Participants were instructed to complete each mission before going on to the next. This prevented participants modifying their answers to a mission in light of subsequent missions. They were free to take less than the requested number of photographs for each mission if they could not find images to suit. They were also allowed to take photographs of the same item for more than one category if required. 
The missions were:

1. To capture images of the 5 things you value most about your home.

2. To capture images of 5 things about your home that save you time.

3. To capture images of 5 things about your home that make you feel safe and secure.

4. To capture images of 5 places where you display information in the home.

5. To capture images of 5 ways you share information with others in the home.

6. To capture images of 3 pieces of technology that you like using, and 3 pieces of technology that you don't like using in the home.

7. To capture images of 5 things you currently do in your home to save energy or help the environment.

In trialling the study packs with participants' own digital cameras, it was found that the clarity of some of the images was such that the finer details of letters, bank or credit card statements and emails captured within the images could be easily defined. Participants were left feeling quite vulnerable and uncomfortable about sharing the images with the researchers. To overcome this, a digital camera with low resolution image capture was purchased specifically for the trial. The camera was chosen for its fun design and simple 'point and shoot' functionality. As they conducted their missions, participants completed the photograph record book, noting down their image selections and a brief explanation of their choices. A total of eight people participated in the study (5 male, 3 female) recruited from the local population. They all had a limited knowledge of Smart Home technology and were considered to fall into the target market group for the TAHI trials.

\section{Analysis Approach}

Gaver et al [21] deliberately avoided systematic analysis of the outputs from their Cultural Probes. As already described, the technical focus of this project required more structured output from the study. Content Analysis provided a practical method for analysing images that did not require the involvement of participants. Krippendorff [22] describes Content Analysis as "making replicable and valid inferences from data to their context". Whilst more usually applied to written documents, Content Analysis is used to analyse images, and was felt suitable for analysing the study outcomes as there was both context (the missions) and content (the photos themselves). When performing a Content Analysis, the recording unit is defined, e.g. themes that occurred within a text, and the output is analysed in detail by noting the occurrence of each theme. Once this is complete, the data can be analysed in various ways. As it is likely that some degree of inference may be required by the researcher [23] more than one independent analysis of the data is recommended and was performed.

The photographs for each mission were sorted into groups of like content, for example, pictures of windows and door locks; pictures of people; pictures of telephones (see Figure 2), and a tally of each category was 
recorded. A total count was also made of how many pictures for each mission were technology-based, as this was a main focus of the research. This approach has similarities to affinity diagramming [24] which can be used for organising the structure of a new system or uncovering the hierarchical structure in a set of concepts. Designers or users write down potential screens or functions on sticky notes and then organise the notes by grouping them and by placing related concepts close to each other. The categorisation described in this paper provided a simplified version of this.

\section{Figure 2 in here.}

The analysis was conducted by two human factors experts, (with reference to the record books where further clarification of the photographs was needed). A third person carried out a further classification activity to produce a single grouping and set of categories, based on the findings of the first two researchers. Where there was significant discrepancy between the opinions of the researchers, the photograph was discussed and a consensus opinion was arrived at. This draws on the validation techniques used in the development of warning symbols, where the meaning of a warning is judged by a panel in this way [25].

In summary, the main steps in the method were as follows:

1. Pictures for each group were printed and separated.

2. Two analysts took each group and 'card sorted' them into categories and gave each category a name.

3. Each group was categorised as technology related and nontechnology related.

4. A third person reviewed the categories and produced a single set to regroup the items appropriately. Consensus was reached where there was significant discrepancy.

5. For some groups more general categories were produced.

6. Each final groupings were reviewed to highlight contextual factors relating to future products.

\section{Results}

The observations and results from each of the missions are presented in the following sections. The photos captured for the first mission are reproduced as a collage; for the remaining missions, a selection of images only is presented, together with comments about the images from the analysis of the data. Results of the Content Analysis are presented in overview in Tables 1 to 7, together with the percentage of images considered to be 'technology' and 'non-technology'. For the purpose of this study, items of 'technology' were regarded as those containing electrical, electronic or computer components.

\section{Things you value most in your home}

The full collage of images collected for this mission is presented in Figure 
3.

\section{Figure 3 in here.}

The participants valued people (in particular family), space and memories most highly. Image selections were consistently associated with terms of comfort, relaxation and sentiment. Of the technology that appeared in the photos, it was the services they provided rather than the physical devices that were valued. For example, the TV was valued for the entertainment it provides and the computer for keeping in touch.

Very little technology was photographed for this mission. The number of images that could be considered technology-based was 17.5\% (7/40) (see Table 1).

Table 1. Content Analysis results - Things you value most

\begin{tabular}{|l|c|l|c|c|}
\hline Relaxation/home comforts & 12 & Technology & 7 & $17.5 \%$ \\
\hline Family & 7 & Non-technology & 33 & $82.5 \%$ \\
\hline Garden/neighbourhood & 6 & & & \\
\hline Living/social space & 5 & & & \\
\hline Appliances & 4 & & & \\
\hline Cars/bikes & 3 & & & \\
\hline Objects/Art & 2 & & & \\
\hline Pets & 1 & & & \\
\hline Total & $\mathbf{4 0}$ & & $\mathbf{4 0}$ & $\mathbf{1 0 0 \%}$ \\
\hline
\end{tabular}

The minor value people placed on technology provided a reminder to the authors and some evidence to the other, technically focused, project partners that, for Smart Home technology to be effective, it must meet the needs and values of the end users. Simply providing a technological solution and expecting people to value it is unlikely to be successful.

\section{Saving time}

\section{Figure 4 in here}

Figure 4 shows a selection of images taken in response to this mission. The returned material contained images depicting mainly technology and automation of household chores, in particular preparation of food and washing of dishes and clothes. Other images captured ways of organising things; for example a mug tree, key hooks, a weekly planner. Clearly technological products have an important role in saving people time in the home. The biggest breakthroughs in terms of time saving are in completing 'household chores' such as washing, cleaning and cooking. However it is interesting that PCs and IT products are not seen as time saving. Perhaps this highlights an opportunity for future product developers. Remote access to appliance control and centralised access to aggregated services were developed for later testing in the project, both of which potentially saved the consumer time and were well received by the users. 
Table 2. Content Analysis - Things that save you time

\begin{tabular}{|l|c|l|c|r|}
\hline Cleaning/washing/tidying & 18 & Technology & 33 & $85 \%$ \\
\hline Cooking/drinks & 9 & Non-technology & 6 & $15 \%$ \\
\hline Comfort/hygiene & 3 & & & \\
\hline Entertainment & 3 & & & \\
\hline Information/communications & 3 & & & \\
\hline Transport & 3 & & & \\
\hline Total & $\mathbf{3 9}$ & & $\mathbf{3 9}$ & $\mathbf{1 0 0 \%}$ \\
\hline
\end{tabular}

\section{Safety and Security}

Figure 5 shows a selection of images in response to the safety and security mission. Most of the returned material could be summed up as 'lights, locks and a line to the outside world'. Several people pictured their partner/spouse or a family member, as they invoke feelings of protection and safety.

\section{Figure 5 in here}

Most objects photographed had a highly visible presence in the participant homes, for example blinds on windows and bolts on doors. Although this may be the result of the visual nature of the task, it might suggest that smoke alarms and carbon monoxide alarms are things that run in the background of the home and are therefore taken for granted, however conclusions should be verified through further research. The terms 'safe' and 'secure' have a broad scope and so participants may have focused on one or other of the terms rather than capturing images that represented both. This illustrates a limitation of the approach, where intentionally little guidance was given to allow participants to make their own interpretation. Technological products are still in the minority compared with barriers such as strong locks, doors, and windows. People may see intruders as a greater hazard than gas and carbon monoxide poisoning. Ways of obtaining help either from other members of the family or by seeking help over the phone is seen as having an important role. It may also reflect the poor trust many people have in the reliability of technology, reflected in other aspects in the project's research. Smart Home safety and security solutions may not be trusted unless demonstrated to be dependable and designs could incorporate appropriate feedback to reassure the consumer.

Table 3. Content Analysis - Things that make you feel safe and secure

\begin{tabular}{|l|c|l|c|r|}
\hline Barriers & 14 & Technology & 14 & $36 \%$ \\
\hline Alerts/Alarms/Deterrents & 14 & Non-technology & 25 & $64 \%$ \\
\hline Communications & 5 & & & \\
\hline Human support & 5 & & & \\
\hline Automatic cut off & 1 & & & \\
\hline Total & $\mathbf{3 9}$ & & $\mathbf{3 9}$ & $\mathbf{1 0 0 \%}$ \\
\hline
\end{tabular}




\section{Displaying information in the home}

Figure 6 shows a selection of images in response to the displaying information in the home mission. Information was consistently shown displayed on notice boards, fridges, by the front door and on sideboards and mantelpieces. Messages are left in different locations chosen because they are integral to the everyday routines of the householders and therefore unlikely to be overlooked. For example, a note left on the stairs to ensure that it is seen as someone walks in the front door or a note left by the kettle so that it is seen in the morning. This finding confirms those of Crabtree and Rodden [14] and Taylor and Swan [26] and supports the need for ubiquitous Smart Home solutions that support the customisable display of information around the home rather than attempting to impose centralised information displays upon the existing household routines of users.

Figure 6 in here.

Table 4. Content Analysis - Places where information is displayed

\begin{tabular}{|l|c|l|c|r|}
\hline Electrical/Electronic & 16 & Technology & 15 & $38 \%$ \\
\hline Handwritten note & 10 & Non-technology & 24 & $62 \%$ \\
\hline Diary/calendar/chart & 8 & & & \\
\hline Highly visible place & 5 & & & \\
\hline Total & $\mathbf{3 9}$ & & $\mathbf{3 9}$ & $\mathbf{1 0 0 \%}$ \\
\hline
\end{tabular}

\section{Sharing information}

Figure 7 shows a selection of images in response to the sharing information mission.

\section{Figure 7 in here}

It was interesting to see that hand written material is still a predominant way of sharing information with others. Apart from the phone and computer to communicate externally, electronic devices are hardly used to share information in the home. Again this may be an opportunity for future developers of Smart Home products. Mobile and landline phones are a popular way of sharing information and featured in much of the returned material for this mission. Images of household calendars and diaries and notes left in different locations around the house again reflected other research findings $[18,26]$.

Table 5. Content Analysis - Ways in which you share information with others

\begin{tabular}{|l|c|l|c|c|}
\hline Hand written & 20 & Technology & 13 & $32.5 \%$ \\
\hline Indirect personal & 8 & Non-technology & 27 & $67.5 \%$ \\
\hline Printed & 5 & & & \\
\hline Electronic display & 4 & & & \\
\hline Personal & 3 & & & \\
\hline Total & $\mathbf{4 0}$ & & $\mathbf{4 0}$ & $\mathbf{1 0 0 \%}$ \\
\hline
\end{tabular}


The images for displaying and sharing information generated from Missions 4 and 5 showed a number of consistencies (e.g. telephones and calendars were included in the photos sets from both missions). Although the two concepts are similar, the missions were addressing different issues. Mission 4 asked for images of where information was displayed and Mission 5 asked how information was shared. Information was displayed where it was most likely to be noticed or not forgotten by the users which, as previously discussed, warns against the introduction of centralised information displays. That half the images depicting how information was displayed showed handwritten notes suggests that users value speed and flexibility when creating information for personal use or for others. Therefore technology solutions that offer potential communication and organisational value to users (for example shared home calendars that can be accessed both from fixed and mobile devices) must also offer rapid and flexible data capture if they are to realistically compete with scribbled notes created by users following the 'path of least resistance'.

\section{Technology likes and dislikes}

Figures 8 and 9 show a selection of images of technology likes and dislikes.

\section{Figures 8 and 9 in here}

Technology likes and dislikes were mainly down to personal choice and the device under judgement. The item types for dislikes was more widespread than for the likes indicating that there is a still a broad scope for ergonomics in the design of consumer devices in the home. While the traditional problem of video programming was evident, it was interesting that there were a large number of audio visual entertainment devices under likes indicating the development of this area towards creating very acceptable and desirable products. Images of wires from the back of the TV/VCR and arrays of remote control devices among the dislikes suggested the aversion people have to the combination of devices and the complexities of networking, rather than a dislike of the specific device. Principles of keeping interfaces simple and consistent were reaffirmed and the authors ensured common interface layouts and navigation systems were included in the development of the Smart Home devices within the project.

Table 6 - Content Analysis - Items of technology you like or dislike

\begin{tabular}{|l|c|l|c|}
\hline Likes & & Dislikes & \\
\hline TV / VCR / multimedia & 7 & Telephone & 4 \\
\hline Telephone & 4 & TV / VCR / Multimedia & 3 \\
\hline Computer & 3 & Remotes - too many! & 2 \\
\hline Microwave/cooker & 2 & Washing machine & 2 \\
\hline Remote control & 2 & Cables at back of TV & 1 \\
\hline Washing machine & 2 & Clock radio & 1 \\
\hline
\end{tabular}




\begin{tabular}{|l|c|l|c|}
\hline Burglar alarm & 1 & Computer printer & 1 \\
\hline HiFi & 1 & Digital Camera & 1 \\
\hline Radio & 1 & Hair straighteners & 1 \\
\hline Waste disposal unit & 1 & Heating controls & 1 \\
\hline & & Hedge trimmer & 1 \\
\hline & & Hi Fi & 1 \\
\hline & & Microwave & 1 \\
\hline & & PDA & 1 \\
\hline Total & $\mathbf{2 4}$ & Total & $\mathbf{2 1}$ \\
\hline
\end{tabular}

\section{Energy saving behaviour and helping the environment}

Figure 10 shows a selection of images in response to energy saving and helping the environment mission.

\section{Figure 10 in here}

Local authority refuse collection techniques prompted participants to capture the recycling bins and boxes featured in many of the photographs, suggesting that recycling now appears to be an accepted part of daily life (within the sample). There appears to be scope for more use of technology to help the householder be more 'green'. Any such device to help in, say, recycling would need to be simple and convenient to use if it is to be accepted as a convenient product or process.

Double glazing, energy saving light bulbs, switching lights off, using economy settings on domestic appliances, putting lids on sauce pans and turning down the thermostat also featured in the material returned for this mission.

Table 7. Content Analysis - Ways to save or help the environment

\begin{tabular}{|l|c|l|c|l|}
\hline Recycling & 11 & Technology & 6 & $15 \%$ \\
\hline Turning down settings & 5 & Non-technology & 34 & $85 \%$ \\
\hline Heating thermostat control & 4 & & & \\
\hline Boiler /tank & 3 & & & \\
\hline Low energy light bulbs & 3 & & & \\
\hline Switching electrical things off & 3 & & & \\
\hline Double glazing & 2 & & & \\
\hline Pan lids & 2 & & & \\
\hline Using shower & 2 & & & \\
\hline Other & 5 & & & \\
\hline Total & $\mathbf{4 0}$ & & $\mathbf{4 0}$ & $\mathbf{1 0 0 \%}$ \\
\hline
\end{tabular}

This mission provided the lowest technology related images. Smart Home technology can offer conflicts between the cost of delivering the technology and the savings it creates. Clearly, any environmental or energy saving device must be obviously 'green' in itself, not just in the functions it performs. 


\section{Discussion of the Approach}

From the collages alone it is possible to see, at a glance, that this method provided an interesting range of responses to the missions. However, in order for the method to have value to support other approaches, it is necessary to consider how well it met its objectives. Each of these is discussed in turn.

Provide a discount method for gaining an understanding of the value and use of technology in different domestic contexts of use

Although the authors' approach was tested at a different stage of the design lifecycle to the "fuzzy front end of design" [27] where Probes approaches have most to offer, the results showed that it can play a useful role in identifying design implications when the design concepts are more established. The Photo Study offered a cost and time effective alternative to ethnographical methods as it did not require researchers to visit participants' homes. For the purposes of the study, it was possible to gain some insight into the range of ways that people responded to the mission questions. The stripped-down version of the Probe technique was effective at allowing an initial analysis of the photographic data, without significant supporting information. The conclusions that can be drawn from the photographs alone are limited, but they are felt to be extremely powerful in response to the stated research questions. In answer to whether people value and use technology in different ways, then it is possible to see the diversity of responses, even with the limited sample used in this study. If the purpose of the research is to identify what might overcome the barriers that may be present, then additional, supporting techniques are needed. Mättelmaki and Battarbee [28] found that asking participants why they chose to create particular photos or other Probes provided responses that led to a deeper understanding of user needs that could not be gleaned from the photos alone. The photo record books, not analysed as part of this study, would provide some additional reasoning behind people's choices of photograph. This should be supported further by individual interviews or focus groups to explore particular issues where time and resources allow.

Gain an insight into people's lives in an unobtrusive way

The Photo Study allowed the participants to be in control of the data they provided. This overcame some of the sensitivity issues often present when collecting data in the domestic environment. The researchers felt they had been given a window into the home in relation to the particular missions, however, the study did not seek to validate this and so it is not possible to identify if someone had shown an accurate or representative picture of themselves. Indeed, it is unlikely that this level of insight could be gained through this method alone.

Provide human factors researchers with inspiration and information on which to develop further Smart Home designs

In common with other uses of Probe studies [16], the Photo Study provided the human factors researchers with further evidence of the diversity of people's lives and homes and how technology is valued and 
integrated into their homes. Understanding this diversity is key to ensuring that new technology introduced into the home is acceptable to everyday consumers as well as early adopters. This method provided an effective and efficient way of reminding the researchers of the diversity of domestic life whilst the structured analysis of the study responses enabled the researchers to begin to make sense of this complexity so that meaningful contributions to design could be offered to the technical project partners.

\section{Provide technical partners with insight into end users' views of technology}

Although the Photo Study worked well as a tool for structuring the thinking of the human factors specialists within the project, it is less clear whether it was effective at providing insight for the technical partners directly. Informing the design of Smart Home technologies within a technology dominated design culture can be difficult, and a technical partner might not fully appreciate the subtleties of the images, although the overall effect of the collages was undeniably powerful. The study aimed to highlight to technologists that everyday consumers do not view or use technology in the same way that they do. Therefore over-specified products for doing simple household tasks are unlikely to be acceptable, when the users already have perfectly good, non-technological ways of doing things. However, the findings also show that a good deal of technology is already in people's homes in the form of domestic appliances and that technology is valued by users when it saves them time and effort. At this level the study met its aim and by providing quantifiable output, helped the technologists come to terms with what are normally unquantifiable issues relating to users' attitudes, values and behaviours in the home.

\section{General tips for applying method}

It is useful to use card sorting to group the pictures into meaningful categories. This was facilitated by printing each picture out as a single small image. It is recommended that at least two analysts separately classify the images and then work together to form a consensus both in terms of grouping and group naming. This paper particularly explores the value of the visual images independently of the data contained in the record book and for this reason the images were analysed without significant recourse to the record book data. However in retrospect, it was felt that a greater depth of understanding could have been achieved by analysis of the record books to ensure the exact meaning of the photo taken was understood; for example, a photo of a treasured item reminding the owner of an enjoyable holiday, rather than just being an attractive trinket. This could be facilitated by replicating the associated user comments on the back of each photo.

Use of the mission format is highly recommended. The packs and sealed mission envelopes intrigued the participants and also broke the study down into manageable activities that could be fitted around other demands in the home such as children and cooking. This made the study less daunting and reduced the likelihood of data collection being put off by the participant until they could see a clear chunk of time to complete the study in one go. The use of the sealed sequential mission envelopes is also 
recommended as it did prevent participants reformulating their answers in relation to the previous questions.

Although the approach gave the authors the confirmation of user diversity they required, greater involvement of the project team would have been worthwhile. This could include a participative approach to the categorisation of the photos, allowing the technical partners to arrive at the themes and involving them with the detail of the approach, rather than just being presented with the results. It would be interesting to see how different stakeholders in a multi-disciplinary project team would categorise images and it is felt that a greater richness of understanding on all sides would be achieved.

\section{Conclusions}

Key findings from this study include:

- People value people, space and memories most highly, rather than technology or physical possessions.

- The items valued most highly were consistently associated with feelings of comfort, relaxation and sentiment.

- Technology and automation are viewed as saving people time and making household tasks easier, rather than adding value.

- Some participants captured images of places or objects that focused on pride, appearance and prestige. Smart Home technologies may invoke the same feelings in some users and, in this way, find their way into people's values.

- People do not display and share information in one single place or using one single technique; people often leave impromptu notes and messages left in context-specific locations around the home. A single, all-encompassing user interface can not adequately support this type of behaviour.

Smart Home technology looks set to become a feature of people's lives, whether it is wanted or not. The availability of technology and development of services with commercial benefits often means that the needs of the end user are treated as secondary. This study, through its novel approach to handling visual data collected using a modified Probe method, aimed to identify what people valued in their home environment. The use of this low cost technique, which involved a structured enquiry, allowed participants to show where technology was of value to them, and where it was not. The Photo Study was felt to provide excellent insight into people's home lives in the areas researched. It is not clear whether this could be translated to a wider survey where missions explored more sensitive issues, but it was a cost-effective exploration which participants enjoyed completing.

Content analysis of the visual data collected using the Probe based approach allowed meaningful reflection upon the role currently played by technology within the home environment in a form appropriate to the needs of the project's technology push development process. Whereas 
researchers and designers during conceptual design wish to be provoked and surprised, during the product specification stage of the development cycle there is a need for tools and techniques that structure the diversity of everyday life and facilitate the translation of user needs into product requirements.

The findings from the Photo Study have implications for the design of future Smart Home technologies and should be carefully considered in order that the consumers' needs are not overlooked within projects striving to overcome considerable technological challenges, particularly in a technology driven project. The home is a treasured possession where people feel secure and comfortable and solutions must be empathic to the home environment.

\section{Acknowledgements}

This work forms part of the TAHI projects, funded by UK's Department for Trade and Industry and project partners. Thanks go to all the participants who took part in the Photo Study.

\section{References}

[1] Ulrich K and Eppinger S (2000) Product Design and Development. McGraw-Hill, USA.

[2] Gaver W, Dunne A and Pacenti E (1999) Cultural Probes. Interactions 6 (1), 21-29.

[3] Frohlich DK (2003) The social context of home computing. HP Laboratories.

[4] Venkatesh A (1996) Computers and other interactive technologies for the home. Communications of the ACM 39:12.

[5] Mateas M, Salvador T, Scholtz J and Sorensen D (1996) Engineering Ethnography in the Home. In CHI '96 Companion Proceedings, 283-284.

[6] Venkatesh A and Vitalari N (1992) Emerging distributed work arrangement: An investigation of computer-based supplemental work at home. Manage. Sci. 38:12, 16871706.

[7] Tweed C and Quigley G (2000) The design and technological feasibility of home systems for the elderly. Research Report, School of Architecture, Queens University, Belfast.

[8] Dewsbury G Taylor B and Edge M (2001) The Process of Designing Appropriate Smart Homes: Including the User in the Design, Scottish Centre for the Environmental Design Research, Robert Gordon University.

[9] Gaver W (2001) Designing for ludic aspects of everyday life. Royal College of Art, UK. [10] Hughes J, King V, Rodden T, Anderson, H (1994) Moving out from the control room: ethnography in system design. CSCW'94, ACM Press.

[11] O'Brien J and Rodden T (1997) Interactive Systems in Domestic Environments. Designing Interactive Systems: Processes, Practices, Methods and Techniques, Amsterdam, The Netherlands, ACM press.

[12] Dray S and Mrazek D (1996) A day in the life of a family: an international ethnographic study. In Field methods casebook for software design. Wixon, D and Ramey, J. Wiley Computer Publishing.

[13] O'Brien J and Rodden T (1999) At home with the technology: an ethnographic study of a set top box trial. ACM Transactions on Computer-Human Interaction (TOCHI) 6 (3):

$282-308$

[14] Crabtree A and Rodden T (2004) Domestic routines and design for the home. Computer Supported Cooperative Work: The Journal of Collaborative Computing. 13 (2), 191-220.

[15] Hofmeester K and de Charon de Saint Germain E (Eds) (1999) Presence: New Media for Older People, Netherlands Design Institute.

[16] Mättelmaki T (2005) Applying probes - from inspirational notes to collaborative insights. CoDesign 1 (2) 83-102 
[17] Hemmings T, Crabtree A, Rodden T, Clarke K and Rouncefield M (2002) Probing the probes. In T Binder, J Gregory and I Wagner (Eds) Proceedings of the Seventh Biennial Participatory Design Conference, Malmo, Sweden 2002 - PDC 2002, 42-50.

[18] Rouncefield M, Crabtree A, Hemmings T, Rodden T, Chevherst K, Clarke K, Dewsbury G and Hughes J (2003) Designing with Care: Adapting Cultural Probes to Inform Design in Sensitrabive Settings. Proceedings of OzCHI 2003, 4-13, Brisbane, Australia: Ergonomics Society of Australia.

[19] Muller M (2003) Participatory design: The third space in HCl. In J. Jacko and A. Sears (eds.), Handbook of $\mathrm{HCl}$. Mahway NJ USA: Erlbaum.

[20] Hutchinson H, Mackay W, Westerlund B, Druin A, Plaisant C et al (2003).

Technology Probes: Inspiring design for and with families. In Proceedings of Conference on Human Factors in Computing Systems (CHI 2003). ACM Press, 17-24

[21] Gaver W, Boucher A, Pennington S and Walker B (2004) Cultural Probes and the value of uncertainty. Interactions 11 (5), 53-56.

[22] Krippendorff K (1980) Content Analysis: An Introduction to its methodology. Newbury Park, Calif: Sage, cited in Robson C (2002) Real World Research: A Resource for Social Scientists and Practitioner-Researchers. Blackwell Publishing.

[23] Robson C (2002) Real World Research: A Resource for Social Scientists and Practitioner-Researchers. Blackwell Publishing.

[24] Beyer H and Holtzblatt K (1998) Contextual Design: Defining Customer-Centered Systems. San Francisco: Morgan Kaufmann Publishers. ISBN 1-55860-411-1

[25] ISO 9186: 2001 Graphical symbols - Test methods for judged comprehensibility and for comprehension.

[26] Taylor A and Swan L (2005) Artful Systems in the Home CHI 2005 Portland, Oregan, USA April 2 -7, 642 -650 ACM Press.

[27] Koskinen I, Mättelmaki T, and Battarbee K (2003) Professional Empathic Design, IT Press, Helsinki.

[28] Mättelmaki T and Battarbee K (2002) Empathy Probes. Proceedings of the Participatory Design Conference, Malmo, Sweden 2002, 266 - 271.

Figure 1. Photo Study Mission Pack

Figure 2. Photo Study Content Analysis

Figure 3. Values images

Figure 4. Saving time images examples

Figure 5. Safety and Security image examples

Figure 6. Displaying information in the home image examples

Figure 7. Sharing information image examples

Figure 8. Technology likes image examples

Figure 9. Technology dislikes image examples

Figure 10. Energy saving and environment image examples 
Figure 1

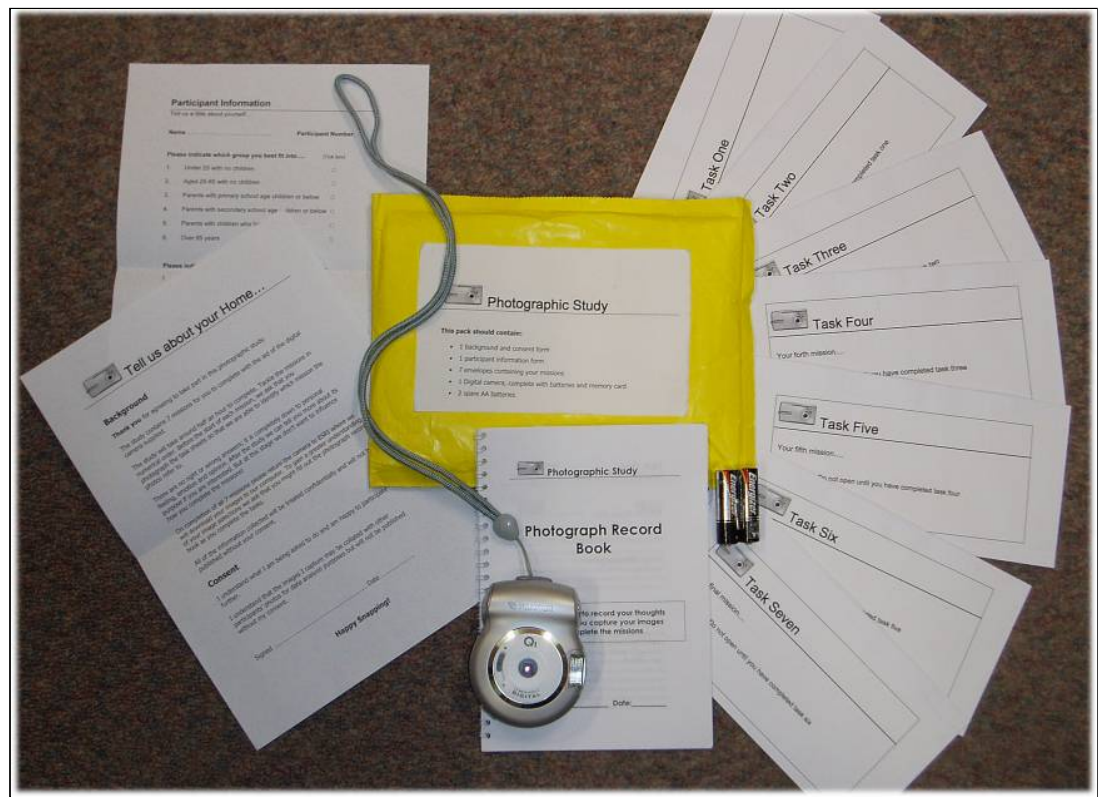

Figure 2

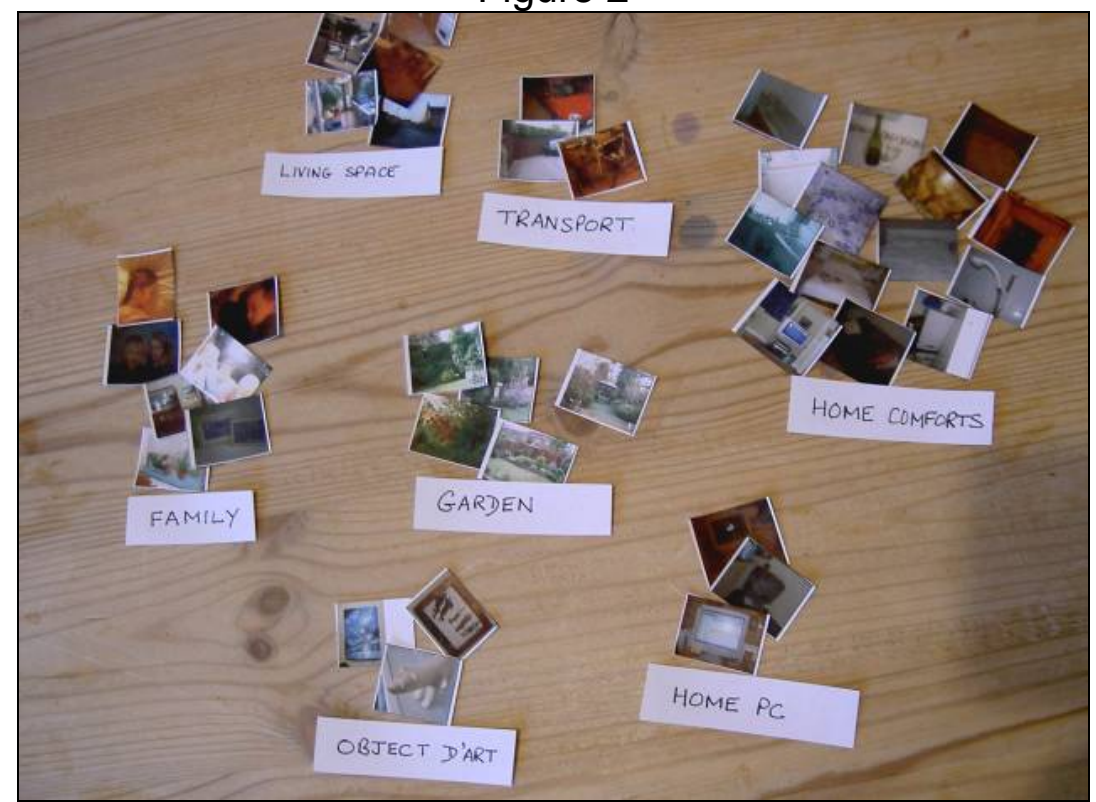

Figure 3

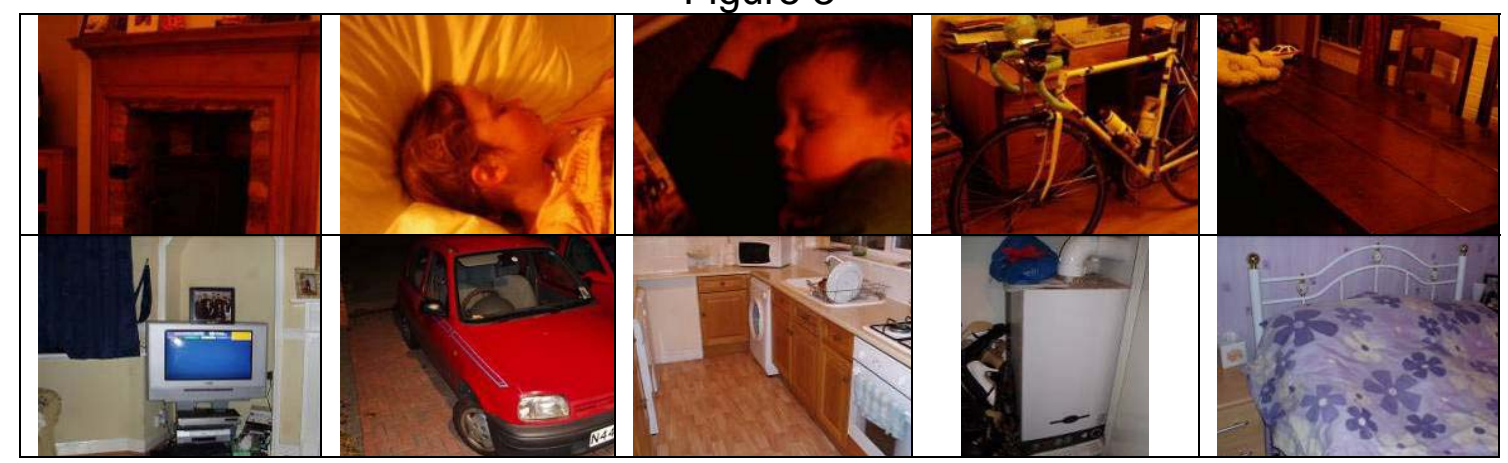




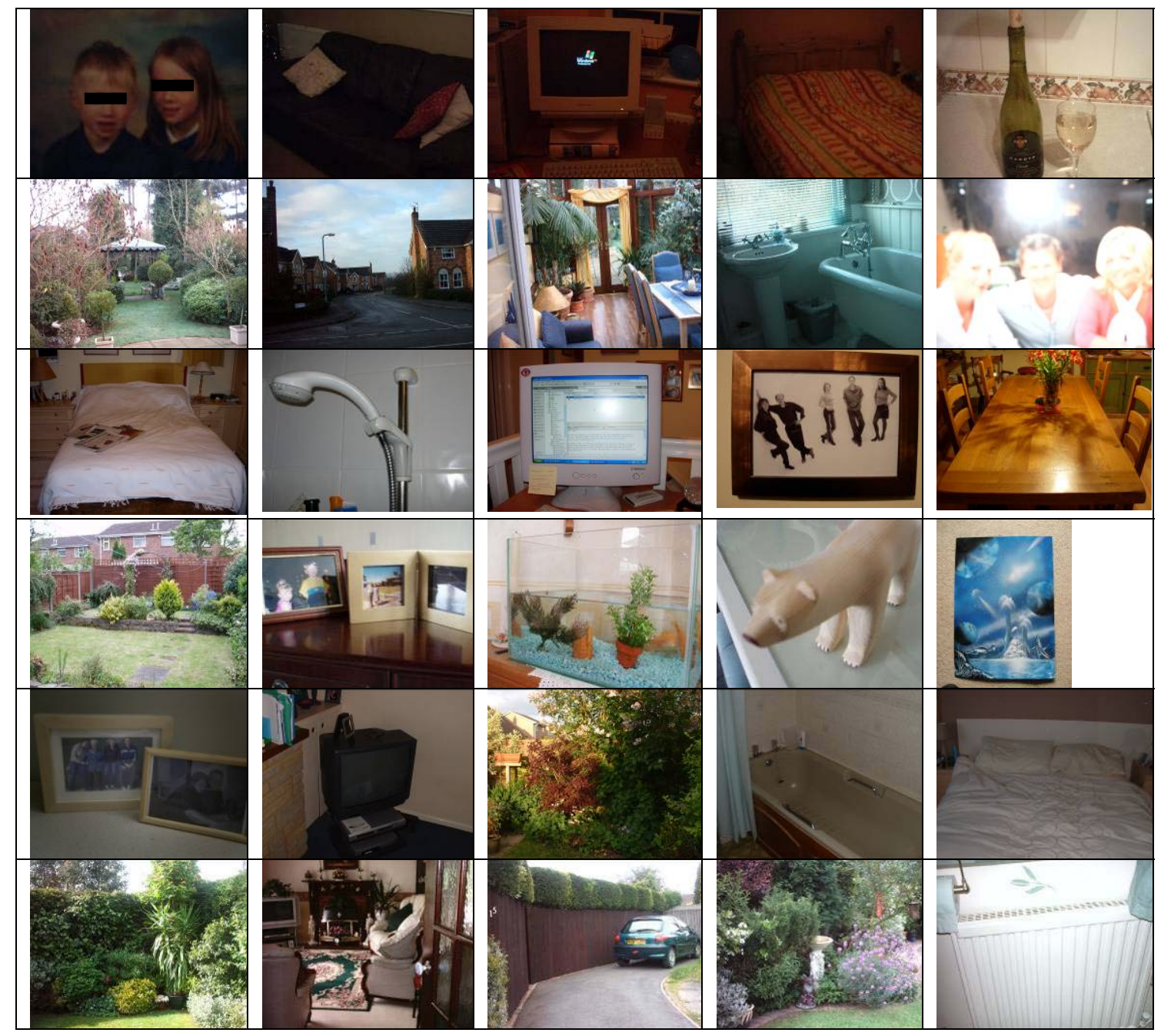

Figure 4

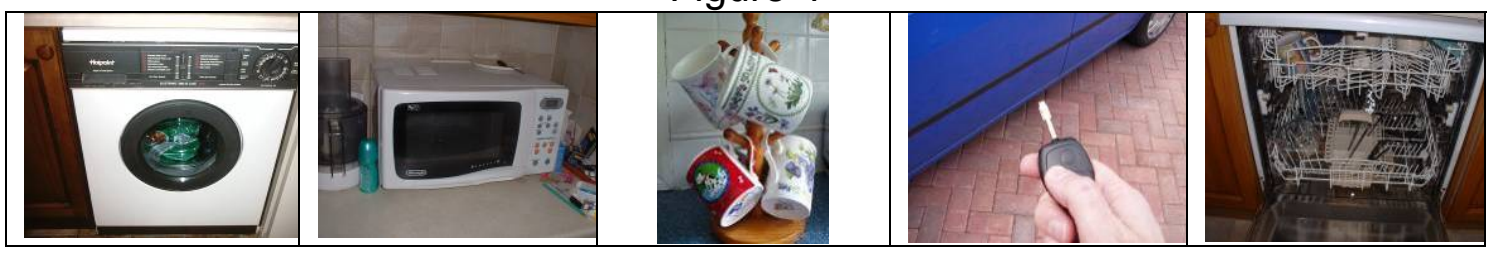

Figure 5

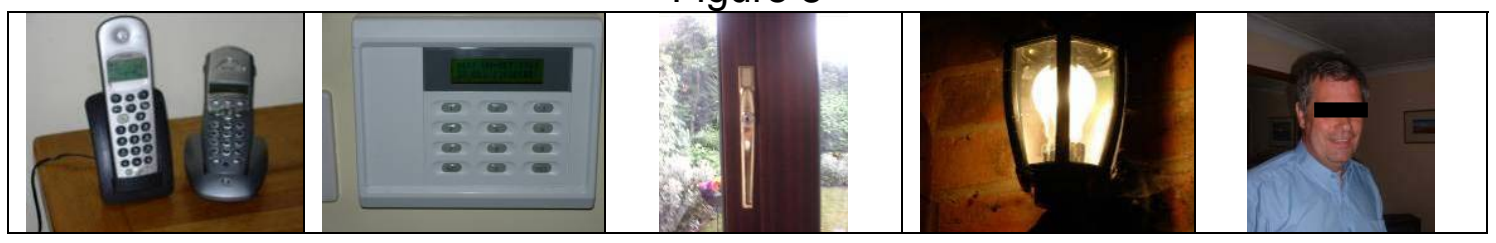

Figure 6

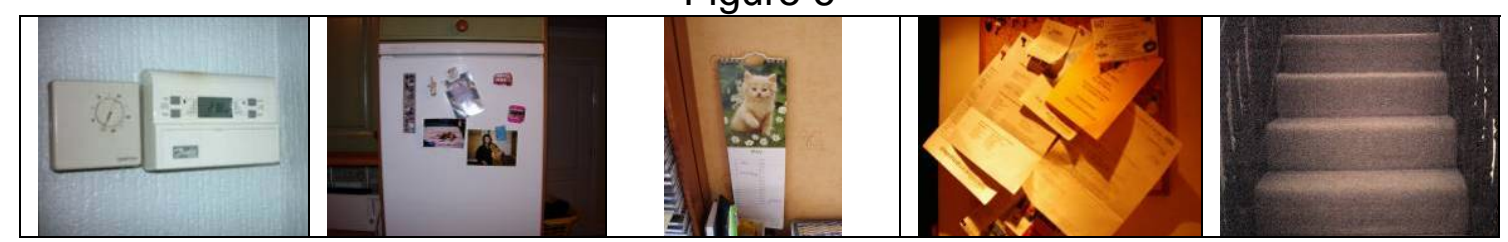


Figure 7

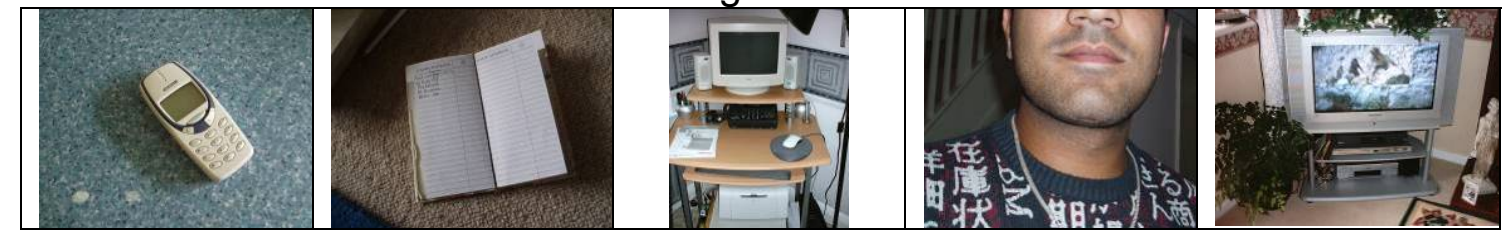

Figure 8

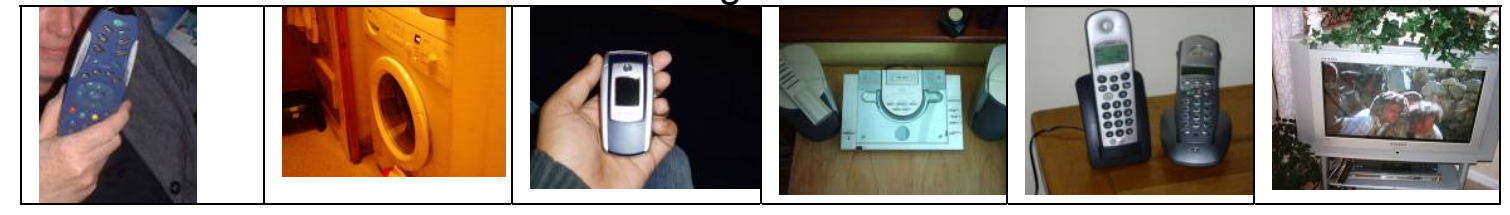

Figure 9

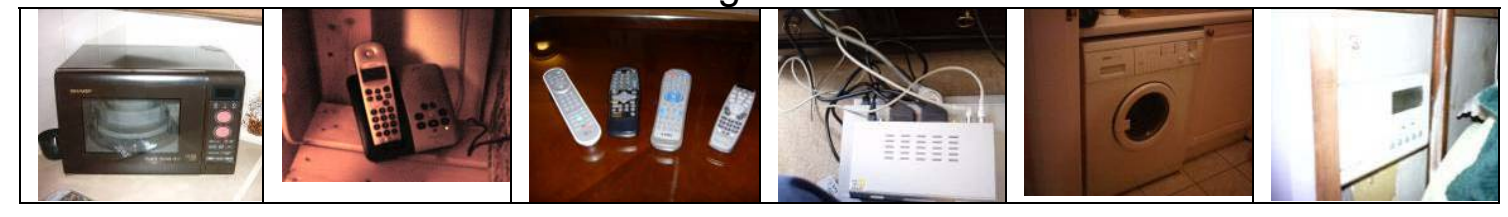

Figure 10

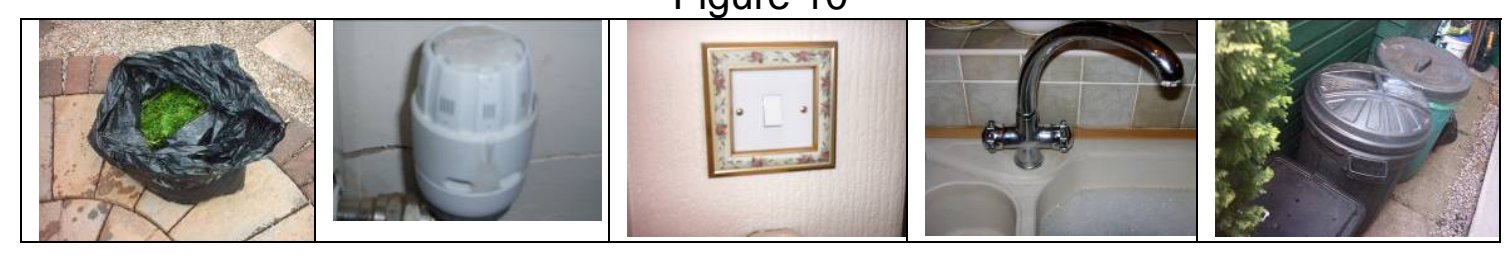

